\title{
The measurement of testosterone in hair
}

\author{
MJ Wheeler, Y-B Zhong, A T Kicman' ${ }^{1}$ and S B Coutts'
}

Department of Chemical Pathology, Guy's and St Thomas' NHS Trust, St Thomas' Hospital, London, SE1 7EH and 'Drug Control Centre, King's College, London, SW3 6LX

(Requests for offprints should be addressed to M J Wheeler)

\begin{abstract}
Trace metals and drugs have been measured in hair for a number of years but there are no published papers on the measurement of steroids in human hair. We report here the measurement of testosterone in hair samples taken from men, women and prepubertal children. This was a preliminary investigation to see whether testosterone was detectable in hair and whether concentrations between men and women, and men and prepubertal children were
\end{abstract}

\section{Introduction}

The analysis of hair for screening heavy metal exposure and heavy metal poisoning is well established. The benefit of hair analysis, over serum or blood analysis, is that, as hair grows about $1 \mathrm{~cm}$ per month (Randall 1994), it can show exposure over the weeks and months. At the end of the seventies and the beginning of the eighties Baumgartner $(1979,1981,1982)$ used hair analysis to detect drug abuse. Initially this work was received with much scepticism but has gradually gained acceptance as other researchers have developed further methods to detect drugs of abuse in hair (Marigo et al. 1986, Muller 1992, Sachs \& Roff 1993, Barnera \& Rossi 1995). One area of drug abuse involves anabolic steroids which are of particular concern in athletics (Bowers \& Segura 1996). At the moment illegal use of these steroids in athletics is screened by the analysis of urine samples. Steroids are cleared from the body rapidly and most orally active steroids are undetectable in the urine after about three days (Schanzer 1996). In anticipation of testing, athletes who take steroids may stop administration a few days before an event to avoid detection. The measurement of anabolic steroids trapped in hair is attractive since it offers an increase in retrospective detection of doping with these hormones. Stanozolol has been detected in rat hair, albeit at doses considerably higher than those likely to be taken by humans on a dose to mass ratio (Hold et al. 1996). To examine the feasibility of measuring steroids in human hair, we have investigated the measurement of testosterone in men, women and children. Testosterone was investigated because of the large (ten fold) difference in serum concentrations of testosterone in men and women. If testosterone concentrations found in hair reflect the concentrations in serum, a difference would be expected different in line with concentrations of testosterone in the blood.

Hair was digested in sodium hydroxide and the testosterone extracted before measurement by radioimmuno- assay. There was a clear difference between testosterone concentrations found in hair collected from men $(12.9-77.7 \mathrm{pmol} / \mathrm{g})$ and those found in hair from women $(<0.9-10.8 \mathrm{pmol} / \mathrm{g})$. There was no significant difference between the concentrations found in women and children. The authenticity of the testosterone measured was confirmed with GCMS.

between testosterone concentrations in male and female hair. Such a finding would make the possibility of detecting xenobiotic anabolic steroids in hair more likely.

\section{Materials and Methods}

\section{Subjects}

Specimens of hair were collected from twenty-two men, aged 21-65 years, nineteen women, aged 17-55 years, and six children aged 5-10 years at the time of a visit to their hairdresser. None of the subjects had dyed or bleached hair. In most cases the subject had their hair washed before cutting. The hair was collected in a clean plastic bag and taken to the laboratory where it was washed in tap water, dried in air, repacked into a clean plastic bag and stored at room temperature until analysis.

No serum was collected from subjects as this study was 1) to examine whether testosterone could be detected in hair and 2) whether any differences in the amount of testosterone between men, women and children reflected the well known differences of testosterone in serum. For the same reasons menstrual function was not recorded in the women.

\section{Analytical methods}

Extraction of testosterone Hair samples were cut into short lengths of about $0.5 \mathrm{~cm}$ from which $50 \mathrm{mg}$ were weighed into glass boiling tubes. Several methods have been used to prewash hair samples (Baumgartner et al.1993). We examined both ether and ethanol. Ten $50 \mathrm{mg}$ samples of a single collection of male hair were washed in $3 \mathrm{ml}$ ether and with $3 \mathrm{ml}$ ethanol. After analysis the results were $82.6 \pm 12.3 \mathrm{pmol} / \mathrm{g}$ (CV 14.9\%) and $85.4 \pm 15.8 \%$ (CV $18.5 \%$ ) respectively. The 
two sets of results were not significantly different but we chose to use ether to wash the hair partly because of the lower imprecision observed and because the hair samples dried more quickly.

To each sample, $3 \mathrm{ml}$ diethyl ether was added and the tube mixed on a rotamixer for about $15 \mathrm{~s}$. The ether was tipped off and when the hair was dry, $1 \mathrm{ml} 1 \mathrm{M} \mathrm{NaOH}$ was added. The tube was placed in a boiling water bath for ten minutes after which the hair was completely dissolved. The tube was allowed to cool and then $5 \mathrm{ml}$ diethyl ether (AR) was added. The hair preparation was extracted for one minute on a rotamixer. The aqueous layer was frozen in a cardice/methanol mixture and the solvent phase poured off into clean glass test tubes. The diethyl ether was evaporated to dryness under air. The extract was re-constituted in $300 \mu \mathrm{l} 0.1 \%$ bovine serum albumin in $0.05 \mathrm{M}$ phosphate-buffered saline (PBS), pH 7.2. To each extract, $100 \mu 10.1 \mathrm{M} \mathrm{NaOH}$ was added followed by $4 \mathrm{ml}$ of an ether:dichloromethane $(3: 2)$ solvent mixture. The steroids were extracted for $1 \mathrm{~min}$ on a rotamixer, and after settling, $3 \mathrm{ml}$ organic phase was taken into clean glass conical test tubes and evaporated to dryness. Blanks were prepared by adding $150 \mu \mathrm{l}$ assay buffer to the digest tubes followed by $1.0 \mathrm{ml} 1 \mathrm{M} \mathrm{NaOH}$. These tubes were taken through the whole procedure and the results subtracted from those of the hair samples.

HPLC After solvent extraction, samples were further purified by HPLC using a Philips Pye Unicam 4020 UV detector with a 4010 pump system. A Radcal medial compression $8 \mathrm{~mm} \mathrm{x}$ $100 \mathrm{~mm} \mathrm{C18}$ cartridge was used with an acetonitrile: water (50:50) solvent system run at $1.0 \mathrm{ml} / \mathrm{min}$. This system gave excellent separation of testosterone, androstenedione and dihydrotestosterone which eluted at 9.1, 11.2 and 15.1 min respectively. 11B-Hydroxy-androstenedione was used as internal standard eluting at $5.7 \mathrm{~min}$.

The dried extract was re-constituted in $50 \mu 1$ of HPLC solvent. The total solution was taken and injected on to the HPLC. Having established the relative retention time of testosterone, appropriate fractions were collected from the HPLC over a three minute period. The column solvent was dried under air and $300 \mu 1$ assay buffer added to reconstitute the steroids. For RIA, $100 \mu$ l buffer was taken. Each sample was extracted in duplicate.

Radioimmunoassay (RIA) The RIA procedure was a slight modification of the method of Wheeler \& Luther (1983). Dried extracts, after purification by HPLC, were reconstituted in $300 \mu \mathrm{l}$ assay buffer (1.0\% BSA in $0.05 \mathrm{M}$ PBS, pH 7.2). An aliquot $(100 \mu \mathrm{l})$ was added to a $12 \mathrm{~mm} \times 75 \mathrm{~mm}$ polystyrene tube and $100 \mu \mathrm{l}$ iodinated testosterone, and $100 \mu \mathrm{l}$ rabbit antitestosterone serum (Guildhay Antisera, Guildford, Surrey, UK) were added. Unextracted standards (0.14-17.5 nmol/L) and extracted quality control specimens were set up at the same time. The tubes were incubated for $2 \mathrm{~h}$ at room temperature. A PEG solution containing $8 \%$ polyethylene glycol (MW 6000), rabbit serum and donkey anti-rabbit immunoglobulin serum was added. After mixing and incubating for $30 \mathrm{~min}$ at room temperature, a further $1 \mathrm{ml}$ assay buffer was added. The tubes were centrifuged for $30 \mathrm{~min}$ at $10^{\circ} \mathrm{C}$ in a refrigerated centrifuge. The aqueous phase was decanted and the tubes left to drain for $1 \mathrm{~min}$. After removing excess liquid, the radioactivity remaining in the precipitate was counted on a LKB Wallac 1216 gamma counter with RIAcalc software (EG\&G Ltd, Milton Keynes, UK). The testosterone concentration of the controls and patient specimens was calculated from the calibration curve. Results were corrected for recovery. The sensitivity of the method was equivalent to $0.9 \mathrm{pmol} / \mathrm{g}$ hair.

Gas chromatography-mass spectrometry (GCMS) Validation of the HPLC/RIA method was carried out by analysing four specimens, purified by solvent extraction and HPLC, by GCMS (Hewlett Packard, Berkshire, UK). A mass selective detector (model 5890/5972) with a cross-linked methyl silicone capillary column (code HP-1; length $25 \mathrm{~m}$, ID $0.2 \mathrm{~mm}$, film thickness $0.11 \mu \mathrm{m}$ ) was used. Testosterone standards $(1 \mathrm{mg} / \mathrm{l}, 500 \mu \mathrm{g} / \mathrm{l}$ and $100 \mu \mathrm{g} / \mathrm{l})$ were prepared in methanol. Appropriate aliquots were dispensed into clean tubes and the methanol evaporated under nitrogen. Distilled water $(5 \mathrm{ml})$ was added to give calibrators with concentrations of 1.5 , $3,6,12,25,50,75$ and $100 \mu \mathrm{g} / \mathrm{l}$, equivalent to $75,150,300$, $600,1250,2500,3750$ and $5000 \mathrm{pg}$ injected into the GCMS. An additional water calibrator containing no steroid was also prepared.

Trideuterated steroid $\left(\left[16,16,17 \alpha_{-}^{-2} \mathrm{H}_{3}\right]\right.$ testosterone $(5 \mathrm{mg} / \mathrm{l})$ was prepared in methanol and $50 \mu \mathrm{l}$ added to each calibrator, quality control and patient specimen to give a final concentration of $50 \mu \mathrm{g} / \mathrm{l}$. The steroids were converted to trimethylsilyl ether (bis-TMS) derivatives under nitrogen by the addition of $50 \mu \mathrm{l}$ of a mixture of iodomethylsilane $(0.2 \%$ $\mathrm{W} / \mathrm{V})$ and dithioerythritol $(0.2 \%)$ in trimethylsilyltrifluoroacetamide and heating to $60^{\circ} \mathrm{C}$ for $15 \mathrm{~min}$. Dry dodecane $(50 \mu \mathrm{l})$ was added to the cooled derivatives and a $1 \mu \mathrm{l}$ aliquot was analysed by selective ion monitoring GC-MS ( $50 \mathrm{~ms}$ dwell time/ion). Samples containing small concentrations of testosterone were concentrated two-fold, prior to analysis, by reducing the derivatisation volume to $25 \mu \mathrm{l}$ and adding an equal volume of dodecane. The amount of internal standard added to these samples was also reduced to $25 \mu$, giving an equivalent final concentration of tri-deuterated testosterone of $50 \mu \mathrm{g} / \mathrm{l}$. Injection was performed in the splitless mode. The flow rate of the carrier gas helium through the column was $0.7 \mathrm{ml} / \mathrm{min}$. The temperatures of the injection port and transfer line were $250^{\circ} \mathrm{C}$ and $280^{\circ} \mathrm{C}$ respectively. The oven temperature was programmed for $180^{\circ} \mathrm{C}$ for $1 \mathrm{~min}$, followed by a $2^{\circ} \mathrm{C} / \mathrm{min}$ increase to $235^{\circ} \mathrm{C}$ and then a $30^{\circ} \mathrm{C} / \mathrm{min}$ rise to $280^{\circ} \mathrm{C}$.

Ratios of the abundance of testosterone to deuterated testosterone were calculated for each calibrator and a calibration curve constructed. The concentrations of testosterone in the controls and patient specimens were determined from the calibration curve; samples with low concentrations of 
testosterone i.e. $<300 \mathrm{pg}$ injected, were interpolated from a reduced calibration curve of range $0-300 \mathrm{pg}$ injected.

Statistics Subject groups were compared using Student's $t$ test.

\section{Results}

Recovery of the method was determined by extracting ten samples of buffer containing $5 \mathrm{nmol} / \mathrm{l}$ testosterone with $1 \mathrm{ml}$ $1 \mathrm{M} \mathrm{NaOH}$, after boiling the solution for $10 \mathrm{~min}$. After extraction and reconstitution, the concentration was measured by RIA. Recovery was found to be $95.9 \pm 2.9 \% \quad(n=10)$ indicating little loss of steroid from the boiling procedure. A further ten samples were treated similarly but purified by HPLC before RIA. Recovery of the method was found to be $72.3 \pm 2.7 \%$. Imprecision was determined by analysing two specimens, with concentrations of $16.1 \mathrm{pmol} / \mathrm{g}$ and $52.6 \mathrm{pmol} / \mathrm{g}$, by HPLC/RIA eight times and was found to be 11.2 and $10.9 \%$ respectively. The comparison of results from

\begin{tabular}{ll}
$\begin{array}{l}\text { Table } 1 \text { Comparison of results } \\
\text { obtained by GCMS and HPLC/RIA }\end{array}$ \\
\hline $\begin{array}{ll}\text { HPLC/GCMS } \\
\text { pmol/g }\end{array}$ & $\begin{array}{l}\text { HPLC/RIA } \\
\text { pmol/g }\end{array}$ \\
\hline 42.69 & 41.1 \\
56.1 & 57.0 \\
530.0 & 828.0 \\
840.0 & 1324.8 \\
\hline
\end{tabular}

the HPLC/RIA method and HPLC/GCMS method is shown in Table 1. Similar results were obtained by the two methods, especially at the low concentrations which were typical of those found in male hair.

Figure 1 displays the results obtained for hair specimens from twenty-two men, nineteen women and six children following HPLC/RIA. There was no significant difference between the testosterone concentrations for women and children. However, the concentrations for both these groups were significantly different $(P<0.001)$ from the concentrations found in male hair and there was no overlap with the latter group.

The concentration of testosterone in hair taken from different areas of the head of two men is shown in Table 2 . The concentrations were similar at all sites and no large differences were observed.

\section{Discussion}

The measurement of drugs of abuse in hair is becoming an accepted, non-invasive, method for detecting drug abuse of a wide range of substances. Hair grows at approximately $1 \mathrm{~cm}$ per month (Randall 1994) and by cutting hair close to the scalp and analysing the drugs in segments at defined distances from the scalp, it is possible to determine the approximate time when drug abuse occurred (Martz et al. 1991). Although most studies have used hair from the scalp, studies have also used beard,

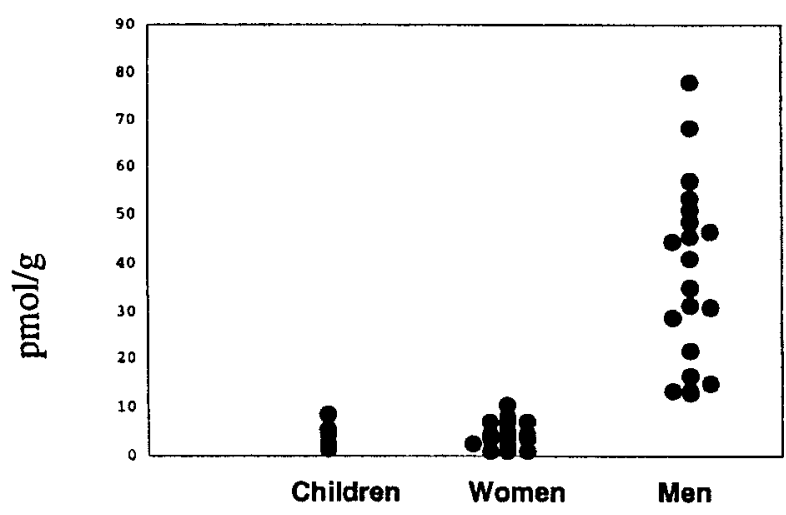

Figure 1 Testosterone concentrations in hair samples from men (34.3 \pm 20.8$)$, women $(4.2 \pm 3.1)$ and children $(5.07 \pm 2.0)$. Values are means \pm S.D. $\mathrm{pmol} / \mathrm{g}$.

pubic and axillary hair (Kintz \& Mangin 1993, Nakahara et al.1993). Hair analysis could have an application in sport as a means of detecting steroid abuse in athletes. Hair is easy to collect and offers a wider window within which steroid abuse could be detected (Martinez 1993). As there is a large sex difference between testosterone concentrations in men and women, and in men and children, we decided to examine the possibility of measuring steroids in hair. At this time we decided to use a very specific method for measuring testosterone, but preliminary studies suggest it may be sufficient to exclude the HPLC step for routine screening. We have shown that the method has adequate precision and the results found in normal subjects correlated well with GCMS analysis. The GCMS method, utilising a mass selective detector quadropole mass spectrometer, did not have the sensitivity to measure the testosterone concentrations found in hair samples from women and children although concentrations in male hair could be measured.

Table 2 Testosterone results $(\mathrm{pmol} / \mathrm{g})$ of scalp hair from five regions from two men

\begin{tabular}{lllll}
\hline Frontal & Temporal & $\begin{array}{l}\text { Vertex } \\
\text { anterior }\end{array}$ & $\begin{array}{l}\text { Vertex } \\
\text { posterior }\end{array}$ & Nape \\
\hline 48.6 & 52.2 & 55.8 & 52.2 & 57.6 \\
46.8 & 45.0 & 54.0 & 66.6 & 52.2 \\
\hline
\end{tabular}

The testosterone concentrations found in hair from men and women, and men and children were significantly different with no overlap in the ranges. The difference between the top of the female range and the bottom of the male range was not as great as one might expect from serum testosterone concentrations. Although the hair was collected from apparently healthy individuals, blood was not collected for testosterone analysis on this occasion. It has also been reported that the concentration of drugs can vary according to the site 
from which hair is collected so that differences in testosterone concentrations between men and women may vary depending on the site of sampling (Kintz \& Mangin 1993). Our preliminary results (Table 2) suggest that there are no large differences in the testosterone concentration of samples taken from different regions of the scalp. We have not yet established whether there are differences between scalp, axillary and pubic hair. A more detailed study is now planned to determine how closely the concentrations of testosterone in hair reflect the testosterone concentration in blood. Since supra-therapeutic doses of anabolic steroids are taken by many abusers our results suggest these compounds can be detected in hair and should be measurable by mass selective detection GCMS, the technique employed by International Olympic Committee Accredited Laboratories. Furthermore, detection may be greatly facilitated by the use of high resolution mass spectrometry (HRMS) which offers greater sensitivity compared to the lower cost quadropole mass spectrometers. HRMS has been very recently employed in the detection of several anabolic steroids in hair collected at the post-mortem of a bodybuilder who abused large amounts of steroid (Thieme $e t$ al. 1998). The measurement of testosterone and other anabolic steroids in hair could be used as an additional test in detecting steroid abuse in athletes when doubt exists over the result of a urine test.

In summary, we have developed a method for the accurate measurement of testosterone in hair. The presence of testosterone has been validated by GCMS and there are clear differences between men and women, and men and children. These results suggest that, not only testosterone, but other abused steroids might be detectable in hair.

\section{References}

Barnera BAM \& Rossi S 1995 Hair and urine analysis: relative distribution of drugs and their metabolites. Journal of Forensic Science International 70 203-210.

Baumgartner AM, Jones PF, Baumgartner WA \& Black CT 1979 Radioimmunoassay of hair for determining opiate-abuse histories. Journal of Nuclear Medicine 20 749-752.

Baumgartner AM, Jones PF \& Black CT 1981 Detection of phencycline in hair. Journal of Forensic Science 26 576-581.
Baumgartner AM, Jones PF, Black CT \& Blahd WH 1982 Radioimmunoassay of cocaine in hair. Journal of Nuclear Medicine 23 790-792.

Baumgartner WA \& Hill VA 1993 Sample preparation techniques. Forensic Science International 63 121-135.

Bowers LD \& Segura J. 1996 Anabolic steroids, athlete drug testing, and the Olympic Games. Clinical Chemistry 42 999-1000.

Höld KM, Wilkins DG, Crouch DJ, Rollins DE, Maes RA 1996 Detection of stanozolol in hair by negative ion chemical ionization mass spectrometry. Journal of Analytical Toxicology 20 345-349.

Kintz P \& Mangin P 1993 Opiate concentrations in human head, axillary and pubic hair. Joumal of Forensic Sciences 38 657-662.

Marigo M, Tagliaro F, Polesi C, Lafisca S \& Neri C. 1986 Determination of morphine in the hair of heroin addicts by high performance liquid chromatography with fluorometric detection. Journal of Analytical Toxicology 10 158-161.

Marting F, Poet TS, Pillai R, Erickson J, Estrada AL \& Watson RR 1993 Cocaine metabolite (benzoylecgonine) in hair and urine of drug users. Journal of Analytical Toxicology 17 138-142.

Martz R, Donnelly B, Lasswell L, Hime GW \& Hearn WL 1991 The use of hair analysis to document a cocaine overdose following a sustained survival period before death. Journal of Analytical Toxicology 15 279-281.

Muller MR. Drug detection in hair by chromatographic procedures. Journal of Chromatography 580 125-134.

Nakahara V, Takahashi K \& Kenuma K 1993 Hair analysis for drugs of abuse. VI. The excretion of methoxyphenamine and methamphetamine into beards of human subjects. Forensic Science International 63 109-119.

Randall VA 1994 Androgens and human hair growth. Clinical Endocrinology 40 439-457.

Sachs H \& Roff I. 1993 Comparison of quantitative results of drugs in human hair by GC/MS. Journal of Forensic Science International $63207-216$.

Schanzer W 1996 Metabolism of anabolic androgenic steroids. Clinical Chemistry 42 1001-1020.

Thieme D, Grosse J, Sachs H, Mueller RK 1999 Detection of several anabolic steroids of abuse in human hair - a case report. Proceedings of the 16th Cologne Workshop on Dope Analysis (to be published).

Wheeler MJ \& Luther F 1983 Development of testosterone assays for routine use. In: Immunoassays for Clinical Chemistry, p113-116. Eds WM Hunter \& JET Corrie. Edinburgh: Churchill Livingstone. 